\title{
Kecemasan Statistika pada Mahasiswa Program Sarjana Pendidikan Agama Islam Universitas Islam Negeri Walisongo Semarang
}

\author{
${ }^{1}$ Dwi Yunitasari, ${ }^{2}$ Muhammad Iqbal \\ ${ }^{1}$ Pendidikan Agama Islam, UIN Walisongo Semarang, Indonesia \\ ${ }^{2}$ IImu Komputer, Universitas Lampung, Indonesia \\ dwi.yunitasari@walisongo.ac.id, muhammadiabal@fmipa.unila.ac.id
}

\begin{tabular}{|c|c|}
\hline ARTICLE & NFO \\
\hline Article Hi & story: \\
\hline Received & : 27-09-2020 \\
\hline Revised & : 23-11-2020 \\
\hline Accepted & $: 25-11-2020$ \\
\hline Online & : 30-11-2020 \\
\hline Keywords & \\
\hline Statistics & Anxiety \\
\hline Statistica & Anxiety Rating \\
\hline $\begin{array}{l}\text { Scale; } \\
\text { Statistics }\end{array}$ & Descriptive \\
\hline
\end{tabular}

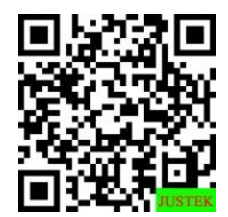

\begin{abstract}
Abstract: The high level of student's statistics anxiety affects the performance of students in the study of statistics. The measurement of statistical anxiety is still rarely done, and the measurement results are also vary. This study explores the level of student's statistical anxiety in the Islamics Education undergraduate program at UIN Walisongo Semarang who took the statistics course in the odd semester of 2020/2021. Research respondents were 70 people. To measure the level of anxiety of statistics students, an instrument of measurement that is used is the Statistical Anxiety Rating Scale (STARS) at the three factors first, namely: Test and class anxiety, Interpretation Anxiety, and Fear of Asking for Help. Observations carried out by way of filling the questionnaire by the students, and analysis of data using analysis of statistics descriptive. Results of the study showed the levels of statistics anxiety for undergraduate student at the Islamic Study of UIN Walisongo Semarang is an amount to $31 \%$. The factors that most trigger statistical anxiety are tests and class activity. If differentiated by the type of sex, then a student of women experiencing anxiety statistics are more substantial than the students of men.
\end{abstract}

\begin{abstract}
Abstrak: Tingginya level kecemasan statistika (statistics anxiety) mahasiswa mempengaruhi performa mahasiswa dalam belajar statistika. Pengukuran kecemasan statistika masih jarang dilakukan, dan hasil pengukurannya juga beragam. Penelitian ini mengeksplorasi level kecemasan statistika mahasiswa pada program sarjana PAI UIN Walisongo Semarang yang mengambil matakuliah statistika pada semester gasal 2020/2021. Responden penelitiannya adalah 70 orang. Untuk mengukur level kecemasan statistika mahasiswa, instrumen pengukuran yang digunakan adalah Statistical Anxiety Rating Scale (STARS) dengan dengan tiga faktor pertama, yaitu:, Test and class anxiety, Interpretation Anxiety, dan Fear of Asking for Help. Observasi dilakukan dengan cara pengisian kuesioner oleh mahasiswa, dan analisis data menggunakan analisis statistika deskriptif. Hasil penelitian menunjukkan level kecemasan statistika mahasiswa program sarjana PAI UIN Walisongo Semarang adalah sebesar 31\%. Faktor yang paling memicu kecemasan statistika adalah ujian dan kegiatan perkuliahan (Test and Class Anxiety). Jika dibedakan berdasarkan jenis kelamin, maka mahasiswa perempuan mengalami kecemasan statistika yang lebih besar dibandingkan mahasiswa laki-laki.
\end{abstract}




\section{A. LATAR BELAKANG}

Salah satu tantangan pengajaran statistika pada bidang sosial adalah tingginya tingkat kecemasan mahasiswa ketika belajar statistika, terutama bagi mahasiswa nonmatematika (Malik, S., 2015)(Paechter et al., 2017). Bukti empiris menunjukkan bahwa mahasiswa dalam disiplin ilmu non-matematika menganggap mata kuliah statistika adalah matakuliah yang paling banyak memicu kecemasan (Chew \& Dillon, 2014). (Auliya, R. N., \& Munasiah, M., 2017) menyatakan bahwa kecemasan statistika akan mempengaruhi kemampuan literasi statistika mahasiswa. Sebuah strategi diperlukan untuk mengatasi kecemasan statistika, jika tidak, maka mahasiswa akan terus-menerus menghadapi masalah ini, dan akan menjadi penghalang bagi kelulusan mereka (Kiss et al., 2019). Berbagai instrumen pengukuran kecemasan statistika, dan metode pengajaran statistika dikembangkan secara terus menerus, yang tujuannya adalah untuk mengurangi tingkat kecemasan dalam belajar statistika, karena tingginya level kecemasan statistika akan mengurangi performa mahasiswa dalam pembelajaran statistika (Lalonde, R. N. \& Gardner, R. C., 1993).

(Cruise, R. J., Cash, R. W., \& Bolton, D. L., 1985)membuat sebuah instrument pengukuran kecemasan statistika, dikenal dengan nama Statistical Anxiety Rating Scale (STARS). (Cruise, R. J., Cash, R. W., \& Bolton, D. L., 1985) telah mengidentifikasi enam faktor kecemasan statistika yaitu: test and class anxiety, interpretation anxiety, fear of asking for help, worth of statistics, computational self-concept, and fear of statistics lecture. Test and class anxiety terdiri dari 8 item, interpretation anxiety terdiri dari 11 item, fear of asked for help terdiri dari 4 item, worth of statistics terdiri dari 16 item, fear of statistics lecture terdiri dari 5 item, dan computational self-concept terdiri dari 7 item. (Hanna, D., Shevlin, M., \& Dempster, M., 2008) merevisi enam item pertanyaan STARS, dan melakukan konfirmasi terhadap factor-faktor yang terbentuk menggunakan confirmatory factor analysis, hasilnya enam factor kecemasan statistika tetap yang terbaik dalam mewakili komponen kecemasan statistika. (Chew \& Dillon, 2014) menyatakan untuk mengukur kecemasan statistika cukup menggunakan tiga faktor pertama dari instrument STARS, yaitu test and class anxiety, interpretation anxiety, fear of asking for help.

Hasil penelitian tentang pengukuran kecemasan statistika bervariasi (Ralston et al., 2020), di antaranya adalah: (Koh \& Zawi, 2014) menemukan bahwa 21.7\% mahasiswa pascasarjana Malaysia mengalami kecemasan statistika dalam beberapa bentuk, (Faradiba et al., 2019) menemukan bahwa 26.6\% mahasiswa calon guru mengalami kecemasan statistika pada empat domain, (Nazliati et al., 2019) menemukan bahwa 11\% mahasiswa nonMatematika FITK IAIN Langsa mengalami kecemasan tahap ringan, 12,5\% tahap sedang, 7\% tahap berat, dan 6.5\% tahap panik, dan (Steinberger, P., 2020) menyatakan bahwa 75\% mahasiswa Ilmu Sosial mengalami kecemasan statistika tingkat sedang hingga tinggi yang ditandai dengan pemikiran yang menggaggu, stress, dan keengganan terhadap konten statistika atau situasi pembelajaran dengan statistika. Untuk mengurangi level kecemasan statistika mahasiswa, pengukuran level kecemasan statistika perlu dilakukan. Oleh karena itu, penelitian ini bertujuan untuk (1) mengukur level kecemasan statistika mahasiswa; (2) Mengidentifikasi faktor yang paling memicu 
kecemasan statistika; dan (3) mengukur level kecemasan statistika berdasarkan jenis kelamin. Studi kasus dilakukan pada mahasiswa program sarjana PAI UIN Walisongo Semarang yang mengambil matakuliah statistika pada semester gasal 2020/2021.

\section{B. METODE PENELITIAN}

Responden penelitian ini adalah mahasiswa Program sarjana PAI UIN Walisongo Semarang semester Gasal 2020/2021. Populasi penelitian berasal dari tiga kelas, yaitu kelas PAI-3D, PAI-3E, dan PAI-U. Jumlah mahasiswa yang menjadi responden adalah 70 orang. Data dihimpun dari responden dengan cara responden diminta mengisi kuesioner STARS secara online. Kuesioner terdiri dari tiga item pertanyaan demografi, dan 23 item pertanyaan kuesioner STARS. Sebanyak 23 item pertanyaan digunakan untuk mengukur besarnya kecemasan mahasiswa saat kuliah statistika.

Dalam penelitian ini, faktor kecemasan statistika yang diukur adalah kecemasan saat ujian (Test and Class Anxiety) yang terdiri dari 8 pertanyaan, kecemasan saat interpretasi tugas (Interpretation Anxiety) terdiri dari 11 pertanyaan, dan kecemasan saat meminta bantuan kepada dosen maupun teman sekelas (Fear of Asking for Help) terdiri dari 4 pertanyaan. Untuk mempermudah interpretasi hasil observasi, setiap item pertanyaan dibuat menjadi dua pilihan jawaban, yaitu cemas dan tidak cemas (Ralston et al., 2020). Variabel penyusun level kecemasan statistika pada STARS merupakan variabel kategorik, oleh karena itu ukuran pemusatan data yang dapat digunakan adalah modus (Lubis, 2020); (WITTE, R. S., 2013).

\section{HASIL DAN PEMBAHASAN}

Mahasiswa yang mengikuti kuliah statistika pendidikan pada program sarjana PAI UIN Walisongo Semarang semester gasal terdiri dari 54\% perempuan dan 46\% laki-laki. Latar belakang pendidikan SMA mahasiswa tersebut adalah 32\% dari jurusan IPA dan $38 \%$ dari jurusan non-IPA. Berdasarkan nilai akhir ujian nasional sewaktu menjadi siswa SMA/MA, 32\% nilai berada di atas rata-rata, dan 38\% sisanya di bawah rata-rata.

Hasil pengukukuran level kecemasan statistika mahasiswa PAI UIN Walisongo Semarang semester gasal 2020/2021 disajikan pada Gambar 1 dan Gambar 2. Dari Gambar 1, level kecemasan statistika saat ujian dan perkuliahan (Test and Class Anxiety) sebesar 56\%, level kecemasan mahasiswa saat menginterpretasikan tugas kuliah (interpretation anxiety) adalah 29\%, dan level kecemasan statistika saat meminta bantuan pada teman sekelas dan dosen (Fear of Asking for Help) adalah sebesar 30\%. Berdasarkan hasil tersebut, faktor pemicu kecemasan statistika yang paling dominan adalah pelaksanaan ujian dan juga perkuliahan (Test and Class Anxiety), yaitu sebesar $56 \%$. 


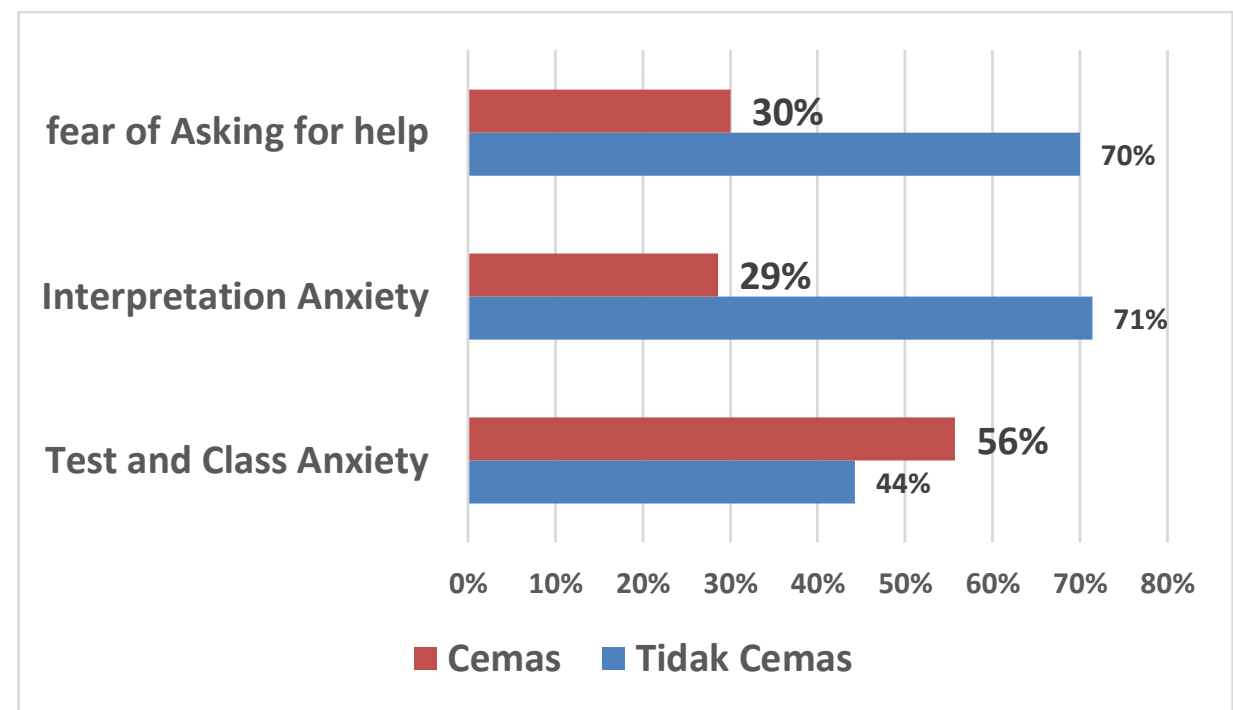

Gambar 1. Bar chart level kecemasan statistika berdasarkan faktor: Test and Class Anxiety, Interpretation Anxiety, dan Fear of Asking for Help.

Secara keseluruhan, hasil pengukuran level kecemasan statistika mahasiswa program sarjana PAI UIN Walisongo Semarang semester gasal 2020/2021 di sajikan pada Gambar 2. Berdasarkan Gambar 2, pada seluruh faktor kecemasan statistika, level kecemasan statistika mahasiswa saat kuliah statistika adalah sebesar 31\%. Artinya 31\% mahasiswa dalam kelas statistika merasakan cemas saat mengambil matakuliah statistika.

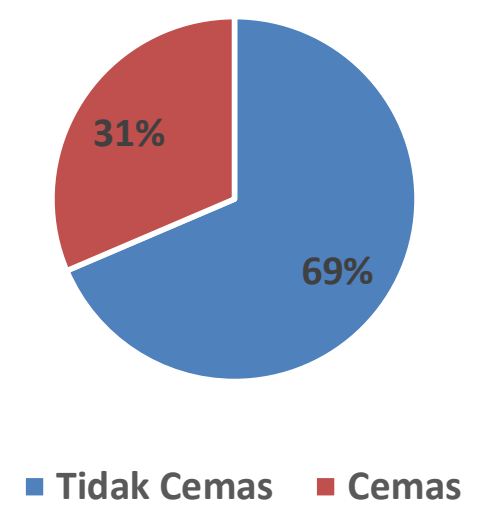

Gambar 2. Level Kecemasan Statistika Mahasiswa Program Sarjana PAI UIN Walisongo Semarang semester Gasal 2020/2021

Dari Tabel 3, Sebesar 37\% mahasiswa perempuan mengalami kecemasan statistika, sedangkan mahasiswa laki-laki hanya 25\%. Dengan demikian, jika pengukuran kecemasan stastistika dibedakan berdasarkan jenis kelamin, maka mahasiswa perempuan mengalami kecemasan statistika yang lebih besar dibandingkan mahasiswa laki-laki. 


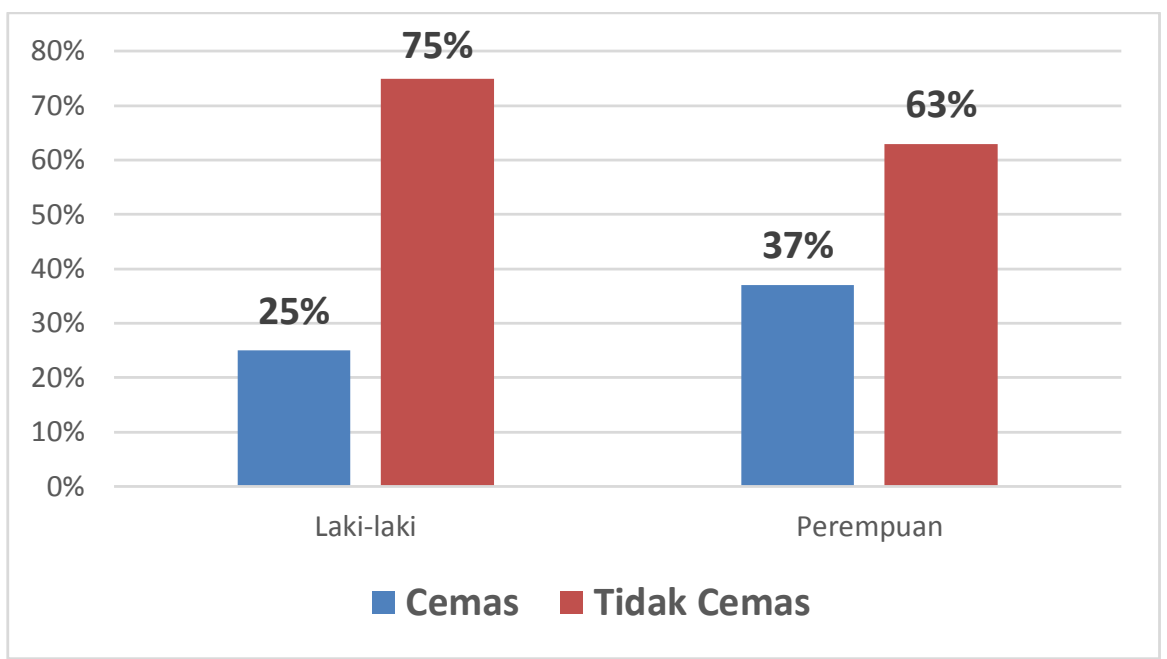

Gambar 3. Level kecemasan statistika mahasiswa dibedakan berdasarkan jenis kelamin

\section{SIMPULAN DAN SARAN}

Berdasarkan hasil penelitian menunjukkan level kecemasan statistika mahasiswa program sarjana PAI UIN Walisongo Semarang adalah sebesar 31\%. Faktor yang paling memicu kecemasan statistika adalah ujian dan kegiatan perkuliahan (Test and Class Anxiety) sebesar 56\%. Jika dibedakan berdasarkan jenis kelamin, maka mahasiswa perempuan mengalami kecemasan statistika yang lebih besar (37\%) dibandingkan mahasiswa laki-laki (25\%).

\section{REFERENSI}

Auliya, R. N., \& Munasiah, M. (2017). Pengaruh Kecemasan... - Google Cendekia. (n.d.). https://doi.org/https://doi.org/10.32502/jp2m.v1i2.1491

Chew, P. K. H., \& Dillon, D. B. (2014). Statistics Anxiety Update: Refining the Construct and Recommendations for a New Research Agenda. In Perspectives on Psychological Science (Vol. 9, Issue 2, pp. 196-208). https://doi.org/10.1177/1745691613518077

Cruise, R. J., Cash, R. W., \& Bolton, D. L. (1985).... - Google Cendekia. (n.d.). Retrieved December 19 , 2020 from https://scholar.google.co.id/scholar?hl=id\&as_sdt=0\%2C5\&q=Cruise $\% 2 \mathrm{C}+\mathrm{R} .+\mathrm{J} . \% 2$ C+Cash\%2C+R.+W.\%2C+\%26+Bolton\%2C+D.+L.+\%281985\%29.+Development+an $\mathrm{d}+$ validation+of+an++instrument+to+measure+statistical+anxiety.+In+Paper+pres ented+at+the+proceedings+of +the+American+Statistical+Association\&btnG=

Faradiba, S., (JPM), S. E. W.-J. P. M., \& 2019. KECEMASAN STATISTIK PADA MAHASISWA CALON GURU. Riset.Unisma.Ac.Id. Retrieved December 19, 2020, from http://riset.unisma.ac.id/index.php/jpm/article/view/3634

Hanna, D., Shevlin, M., \& Dempster, M. (2008). The... - Google Cendekia. (n.d.). Retrieved December 19 , 2020 , from https://scholar.google.co.id/scholar?hl=id\&as_sdt=0\%2C5\&q=Hanna\%2C+D.\%2C+ Shevlin\%2C+M.\%2C+\%26+Dempster\%2C+M.+\%282008\%29.+The+structure+of+t he+statistics+anxiety++rating+scale $\% 3 \mathrm{~A}+\mathrm{A}+$ confirmatory+factor+analysis+using+ $\mathrm{UK}+$ psychology+students.+Personality+and+individual+differences $\% 2 \mathrm{C}+45 \% 281$ $\% 29 \% 2 \mathrm{C}+68-74 \& \mathrm{btnG}=$ 
Kiss, A., Harari, R., \& Vukovic, R. (2019). Reducing the Impact of Statistics Anxiety in College Classrooms. https://commons.mtholyoke.edu/wpcontent/uploads/sites/426/2019/01/Reducing-the-Impact-of-Statistics-Anxiety1.pdf

Koh, D., \& Zawi, M. K. (2014). Statistics Anxiety among Postgraduate Students. International Education Studies, 7(13), 166-174. https://doi.org/10.5539/ies.v7n13p166

Lalonde, R. N. \& Gardner, R. C. (1993). Statistics... - Google Cendekia. (n.d.). Retrieved December 2020 , from https://scholar.google.co.id/scholar?hl=id\&as_sdt=0\%2C5\&q=Lalonde\%2C+R.+N.+ $\% 26+$ Gardner $\% 2 \mathrm{C}+\mathrm{R} .+\mathrm{C} .+\% 281993 \% 29 .+$ Statistics+as+a+second+language $\% 3 \mathrm{~F}+\mathrm{A}$ +model+for++predicting+performance+in+psychology+students.+Canadian+Journa l+of+Behavioural+Science $\% 2 \mathrm{C}+25 \% 2 \mathrm{C}+108-125 . \& \mathrm{btnG}=$

Lubis, R. (2020). Ukuran Pemusatan Data. https://repository.unikom.ac.id/63568/1/STAT 05 \%28Ukuran Pemusatan Data\%29.pdf

Malik, S. (2015). Undergraduates' Statistics Anxiety:... - Google Cendekia. (n.d.). Retrieved December 19 , 2020

from https://scholar.google.co.id/scholar?hl=id\&as_sdt=0\%2C5\&q=Malik\%2C+S.+\%282 015\%29.+Undergraduates $\% 27+$ Statistics+Anxiety $\% 3 \mathrm{~A}+\mathrm{A}+$ Phenomenological++Stu dy.+Qualitative+Report $\% 2 \mathrm{C}+20 \% 282 \% 29 \& b \operatorname{tnG}=$

Nazliati, N., Sari, R., Pendidikan, F. F.-J. D., \& 2019. Diagnosis Kecemasan Statistik Pendidikan Pada Mahasiswa Non-Matematika FTIK IAIN Langsa. 103.52.61.43. Retrieved December 19, 2020, from http://103.52.61.43/index.php/dedikasi/article/view/116

Paechter, M., Macher, D., ... K. M.-F. in, \& 2017. Mathematics anxiety and statistics anxiety. Shared but also unshared components and antagonistic contributions to performance in statistics. Frontiersin.Org. Retrieved December 19, 2020, from https://www.frontiersin.org/articles/10.3389/fpsyg.2017.01196/full

Ralston, K., Gorton, V., MacInnes, J., Gayle, V., \& Crow, G. (2020). Anxious women or complacent men? Anxiety of statistics in a sample of UK sociology undergraduates. International Journal of Social Research Methodology. https://doi.org/10.1080/13645579.2020.1761186

Steinberger, P. (2020). Assessing the Statistical... - Google Cendekia. (n.d.). Retrieved December 19, 2020, from https://scholar.google.co.id/scholar?hl=id\&as_sdt=0\%2C5\&q=Steinberger\%2C+P.+ $\% 282020 \% 29 .+$ Assessing+the+Statistical+Anxiety+Rating+Scale+as+applied+to++ prospective+teachers+in+an+Israeli+Teacher-

Training+College.+Studies+in+Educational+Evaluation $\% 2 \mathrm{C}+64 \% 2 \mathrm{C}+100829 \& \mathrm{btnG}$ $=$

WITTE, R. S. (2013). a John S. WITTE. Statistics.... - Google Cendekia. (n.d.). Retrieved December 19, 2020, from https://scholar.google.co.id/scholar?hl=id\&as_sdt=0\%2C5\&q=WITTE\%2C+R.+S.+ $\% 282013 \% 29 .+a+J o h n+$ S.+WITTE.+Statistics.+Hoboken+NJ.\&btnG= 